\title{
LOS ROSTROS DE MENGORE. ANTROPOLOGÍA TEOLÓGICA DESDE EL VÍA CRUCIS DE MARKO I. RUPNIK
}

Fecha de recepción: 12 de enero de 2020

Fecha de aceptación: 15 de abril de 2020

RESUMEN: El arte de Marko I. Rupnik, uno de los principales artistas al servicio de la Iglesia, no resulta a primera vista asombroso. No es un arte para admirar, sino un arte de la presencia, capaz de poner en diálogo el arte paleocristiano y bizantino con el lenguaje de las vanguardias. Esta investigación se centra en las connotaciones teológicas y antropológicas que se pueden extraer del vía crucis que realizó en 2008, en su Eslovenia natal; unos mosaicos formados exclusivamente por rostros, en los que unos grandes ojos, más allá de interpelar al peregrino, le hablan de la constitución más profunda del ser humano y de la vocación a la que está llamado.

PALABRAS CLAVE: rostro; máscara; vía crucis; Marko Ivan Rupnik; ojos; mosaico.

\section{Mengore's Faces. The Theological Anthropology of Marko I. Rupnik's Way of the Cross}

ABSTRACT: The art of Marko I. Rupnik, one of the foremost artists at the service of the Catholic Church, does not strike the viewer at first sight. It is not an art to be admired, but an art of the presence. He is able to link early Christian and Byzantine art with the language of avant-garde artists. This article focuses on the

\footnotetext{
*Centro Tajamar: jmcarrion@tajamar.es
} 
theological and anthropological implications of the way of the cross he made in 2008 in his native Slovenia. The mosaics, used exclusively to represent wide-eyed faces, do not only call the attention of pilgrims, but also tell them about what lies deep inside every human being, as well as about the vocation to which all men are called.

KEY WORDS: face; mask; way of the Cross; Marko Ivan Rupnik; eyes; mosaic.

\section{INTRODUCCIÓN}

La colina de Mengore es un alto perdido en medio de los Prealpes Julianos, por encima de Volče, junto al río Isonzo, al oeste de Eslovenia. Un entorno boscoso, de verdes frondas, parece querer acallar los enfrentamientos habidos cien años atrás, en aquellas laderas del frente austro-húngaro, durante la Gran Guerra. Testimonio de ello son en cambio las cuevas y trincheras, una serie de monumentos conmemorativos e, incluso, un cementerio militar. Todo ello constituye el Muzej na prostem Mengore, Museo al aire libre de la Primera Guerra Mundial.

Los azotes no se limitan en el tiempo solo al siglo pasado. Históricamente se ha tratado de una zona muy castigada por desastres tanto naturales como bélicos, lo que ha hecho de la Iglesia de Santa María, en lo alto de Mengore, un lugar de refugio y peregrinación para las gentes de la región.

En 1932, cuatro años después de su reconstrucción tras la Primera Guerra Mundial, se hicieron unas capillas con las estaciones del vía crucis, quedando arruinadas en $1954^{1}$. Era importante que en un escenario de tanto dolor se abriese un camino de luz y de esperanza; de ahí la decisión de levantar nuevamente el vía crucis. La obra fue realizada en 2008 por el padre Marko I. Rupnik, SJ (Zadlog, 1954) y los artistas del Centro Aletti².

\footnotetext{
1 Algunos nobles a su regreso de las Cruzadas quisieron realizar en sus regiones de origen reproducciones de los santos lugares; así nacen los vía crucis y «calvarios»: capillas y cruces que se alzan sobre los montes rememorando el lugar donde fue crucificado Jesucristo. Suele ser habitual que haya un vía crucis en su ascenso, como ocurre en Mengore, cuyas estaciones jalonan el camino que sube desde Volče hasta la Iglesia de Santa María.

2 A mediados de los noventa, san Juan Pablo II encomendó al padre Rupnik la dirección del Taller de arte espiritual del Centro Ezio Aletti, con la intención de dar un impulso revitalizador a la iconografía cristiana, buscando la vinculación entre la tradición oriental y la occidental (cf. María Ruiz de Loizaga. "La reinterpretación del
} 
El vía crucis de Mengore consta de catorce mosaicos, uno por cada estación ${ }^{3}$. Si bien el número de estaciones que configuran el camino de la cruz ha variado durante la historia, será a partir del siglo XVI cuando por el sur de Europa empiecen ya a darse devocionarios con catorce estaciones ${ }^{4}$.

Las escenas de la Pasión han sido motivo tradicional del arte pictórico y escultórico; hasta el siglo XIX, la gran mayoría de los artistas afrontó algún episodio de las mismas en modo realista, con una gran profusión de personajes que componían las escenas de forma más o menos teatral. Conforme avanzaba el tiempo la tentación kitsch del sentimentalismo o del didactismo simplón se hizo más patente. No es esto lo que se va a observar en las capillas de Mengore.

El presente trabajo pretende sacar a la luz - a partir del estudio general del conjunto de Mengore y, más particularmente, de las estaciones I, IV, XI y XII- algunos aspectos del pensamiento del artista-teólogo esloveno tanto en el ámbito del lenguaje y retórica visuales, como en un contexto más próximo a la antropología teológica.

\section{ROSTRO Y PERSONA}

\subsection{Statio I. Iesus CONDEMnatur aD MORTEM}

Acusador, juez y víctima (fig. 1); tres rostros unidos por una misma base: la cruz. Tres miradas: la del acusador, de soslayo a quien observa la escena; la del juez, polarizada por el personaje anterior; y la de la

descenso de Cristo a los infiernos en los mosaicos litúrgicos del Centro Aletti”. Estudios Eclesiásticos, n. ${ }^{\circ} 94$ (2019): 445-447).

3 El término «estación» - loca stacionum - aparece por primera vez en el relato que el inglés William Wey hace de su peregrinación a Tierra Santa: el orante se detiene o «estaciona» unos momentos para considerar la escena allí vivida.

${ }^{4}$ La configuración definitiva del vía crucis es fruto de la unión de tres devociones precedentes: las caídas de Cristo en su recorrido hacia el Locus Calvariae; la vía dolorosa, consistente en la procesión desde una iglesia a la próxima; y las estaciones de Cristo, en referencia a las paradas que realizó el Señor en este recorrido (The Way of the Cross, Piero Marini. Última modificación: 1 de febrero de 2011. Fecha de consulta: 15 de enero de 2019. http://www.vatican.va/news_services/liturgy/documents/ ns_lit_doc_via-crucis_en.html). 
Víctima, directa y frontal — frontalidad que significa presencia- hacia el peregrino que ha comenzado el recorrido del vía crucis. Una posición de la mirada de Cristo solo similar a la que se vuelve a ver en la estación vI, donde Verónica muestra al mundo el premio a su piedad ${ }^{5}$.

La persona aflora, se concentra y condensa en el rostro; el cuerpo converge en el rostro ${ }^{6}$ : podría considerarse al rostro como «una singular abreviatura de la realidad personal en su integridad ${ }^{7}$ :

«Mi rostro es también la parte de mí a la que otros dirigen su atención cuando se dirigen a mí como "tú". Yo estoy detrás de mi rostro, pero a la vez estoy presente en él, hablando y mirando a través de él a un mundo de otros que también se revelan y ocultan al mismo tiempo, como yo» ${ }^{8}$.

Una imagen siempre es más o menos cautiva de su forma plástica, pero - siguiendo a Lévinas- la epifanía del rostro es viviente, es una visitación:

«El Otro que se manifiesta en el rostro, perfora, de alguna manera, a su propia esencia plástica, semejante a alguien que abrirá la ventana en la que su figura ya se vislumbraba. Su presencia consiste en desvestirse de la forma que, sin embargo, ya lo manifestaba. Su manifestación desborda la parálisis inevitable de la manifestación. Es esto lo que describimos por la fórmula: el rostro habla. La manifestación del rostro es el primer discurso. Hablar es, ante todo, esta manera de venir desde atrás de su apariencia, desde detrás de su forma, una apertura en la apertura»?.

Para el pensador lituano, el rostro -más allá de los rasgos fisonómicos- es una categoría metafísica y ética. En el rostro se hace presente el hombre sin intermediarios, con absoluta inmediatez:

«En este sentido, puede decirse que el rostro no es "visto". Es lo que no puede convertirse en un contenido que vuestro pensamiento abarcaría; es lo incontenible, os lleva más allá» ${ }^{10}$.

5 Sobre el manto de Verónica cf. Fermín Labarga. "El rostro de Cristo en el arte”. Anuario de Historia de la Iglesia 25 (2016): 274-278.

${ }^{6}$ Marko Ivan Rupnik. Los colores de la luz. Burgos: Monte Carmelo, 2003, 82.

7 Julián Marías. Antropología metafísica. Madrid: Ediciones de la Revista de Occidente, 1970, 172.

${ }^{8}$ Roger Scruton. El alma del mundo. Madrid: Ediciones Rialp, 2016, 152-153.

9 Enmanuel Lévinas. Humanismo del otro hombre. México: Siglo Veintiuno editores, $1974,59$.

${ }^{10}$ Enmanuel Lévinas. Ética e infinito. Boadilla del Monte: A. Machado Libros, $2008,72$. 


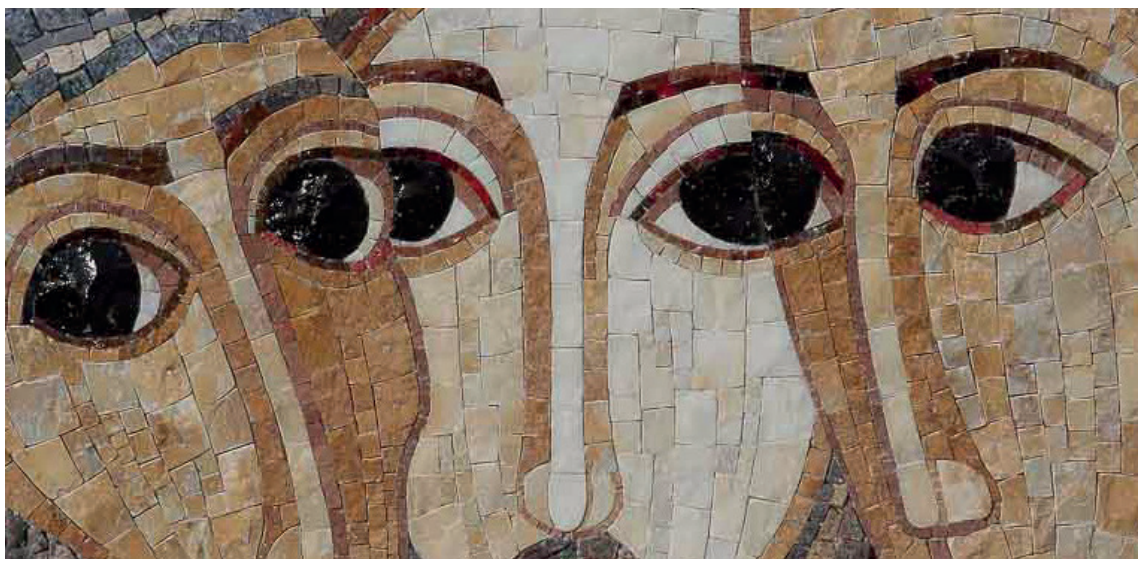

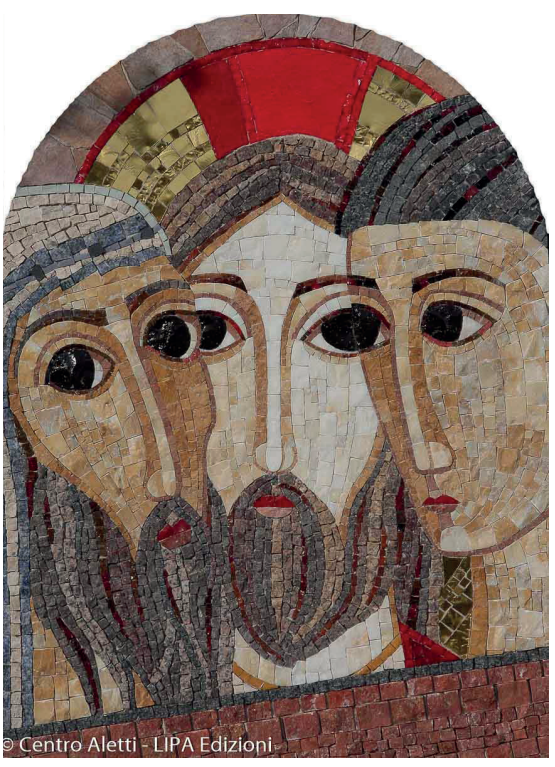

(C) Centro Studi e Ricerche Ezio Aletti, 2020 http://www.centroaletti.com

La mirada del rostro de Cristo trasciende el tiempo, aunque los tiempos traten de opacarla, de ocultarla tras un telón, como la disposición que adoptan los rostros de los personajes laterales. Cristo es la Luz; Pilatos y el personaje judío están a contraluz, son oscuridad: «en Él estaba la 
vida, y la vida era la luz de los hombres. Y la luz brilla en las tinieblas, y las tinieblas no la recibieron» (Jn 1,4-5):

«Está claro que el pecado hace que el hombre perciba a Dios como un límite a su propia gestión de las cosas. [...] Gestionar el mundo según su propia voluntad: una especie de autonomía radical proclamada por el hombre convierte a Dios en su mayor enemigo» ${ }^{11}$.

Es interesante el detalle del solapamiento del ojo de Pilatos con el de Cristo; vale la pena compararlo con el de la estación Iv. Pilatos, que siendo juez había reconocido al Inocente, no ha querido aceptar a la Verdad: aparta su mirada hacia la del acusador, a quien desea complacer; el giro de su voluntad queda aquí representado en esos dos ojos que se llegan casi a fundir, haciéndose más patente su desajuste precisamente por el contraste del negro respecto de su alrededor.

El hombre es un ser personal, un alguien corporal, capaz de relación ${ }^{12}$; más aún, capaz de comunión. La función reflexiva de la conciencia humana - aquella por la que se vuelve hacia el sujeto- permite al hombre no solo conocerse, sino "vivirse interiormente a sí mismo como "yo", como sujeto de los propios actos y de las propias experiencias» ${ }^{13}$.

La persona posee un «yo», una subjetividad: el sujeto se da a sí mismo como «yo» precisamente en la experiencia vivida de la subjetividad ${ }^{14}$. Conviene resaltar también, siguiendo a Millán-Puelles, que «la subjetividad es, y se vive, cuerpo; y en el encuentro con el alter ego vive también su cuerpo como vivido por otro» ${ }^{15}$; «mi cuerpo» no es algo que solo «tengo», sino que «soy». Aunque es cierto que puede darse una cierta objetivación del cuerpo, no cabe una objetivación plena pues «ello escapa al poder de la

${ }_{11}$ Marko Ivan Rupnik. El camino de la vocación cristiana. Madrid: BAC, 2016, 30-31.

12 El hombre no existe fuera de su naturaleza, pero tampoco queda reducida a ella. Por eso es persona: no se trata de una categoría biológica sometida a la naturaleza; en tal caso habría que hablar de individuo. Afirma Rupnik que el individuo es una confusión entre la persona y la naturaleza producto del pecado (cf. Tomáš Špidlík, y Marko Ivan Rupnik. Teología de la evangelización desde la belleza. Madrid: BAC, 2013, 164).

13 Juan Manuel Burgos, ed. La filosofía personalista de Karol Wojtyla. Madrid: Palabra, 2011, 130.

14 Karol Wojtyla. Persona y acción. Madrid: Palabra, 2011, 89.

15 Antonio Millán-Puelles. La estructura de la subjetividad. Madrid: Ediciones Rialp, 1967, 385. 
subjetividad, que no puede nunca objetivarse de una manera exhaustiva [...], ni siquiera en la reflexión» ${ }^{16}$.

Tampoco todas las zonas del cuerpo humano son igualmente objetivables; en el caso del rostro y la mirada, la objetivación resulta especialmente dificultosa (aunque no imposible). Marías hace una interesante observación apoyándose en la finura lingüística: el rostro humano es mínimamente sexual y máximamente sexuado: la actividad sexual, que ocupa una franja limitada dentro de la biografía de cada persona, se funda «en la condición sexuada de la vida humana en general, que afecta a la integridad de ella, en todo tiempo y en todas sus dimensiones ${ }^{17}$.

El rostro es epifanía de la persona, sinécdoque singular de ella. La interioridad de la persona aparece en el rostro: «animi est enim omnis actio et imago animi vultus, indices oculi», dirá Cicerón. La persona se comunica con la realidad a través de su interioridad, dada — siguiendo a Millán-Puelles_ la estructura reiforme de la subjetividad que es y se vive cuerpo:

«El término "persona" se ha escogido para subrayar que el hombre no se deja encerrar en la noción "individuo de la especie", que hay en él algo más, una plenitud y una perfección de ser particulares, que no se pueden expresar más que empleando la palabra "persona" $»^{18}$.

\subsection{El Rostro humano: ¿SEMBlante o MÁscara?}

La cultura griega refería con el término prósōpon — «lo que está ante la mirada de otros» - tanto el rostro como la máscara; cara y careta resultaban sinónimos. Serán los romanos quienes posteriormente distingan entre «prósōpon-máscara», persona, y «prósōpon-rostro», rostrum ${ }^{19}$. ¿Por qué nombrar con el latín persona a la máscara? Persona derivaría de personare — «sonar a través de algo»—: persona sería la máscara teatral hueca con una especie de bocina que, a modo de caja de resonancia, alzaba la voz del actor. No obstante, hay otras hipótesis que prefieren

16 Ibid., 389.

17 Ibid., 160.

18 Karol Wojtyla. Amor y responsabilidad. Madrid: Editorial Razón y Fe, 1978, 14.

19 Se sigue la etimología que indica la RAE para el término «rostro». Otra procedencia es la del término vultus. 
enraizar persona con el término etrusco phersu, que significaba también máscara ${ }^{20}$.

El término rostrum resulta paradójico por aludir al pico u hocico puntiagudo de un animal, lo que es contrario a una de las señas de identidad del hombre: un animal sin hocico. Las diferencias entre rostro (humano) y jeta (animal) responden a importantes causas, pues existe una profunda interrelación entre el hecho de la bipedación, las manos y el rostro ${ }^{21}$ : «el bipedismo es la liberación de la mano [...]. Si hay hocico, no hay mano (con hocico, el animal se inclina, es cuadrúpedo). Sin cara no hay mano, y sin mano no hay cara. El rostro y la mano constituyen un sistema ${ }^{22}$.

Que el hombre fabrique instrumentos - e, incluso, metainstrumentos- refleja que se trata de un ser especial, una inteligencia vigilante capaz de descubrir oportunidades. Sin embargo, manos y rostro resultan ser dos manifestaciones mucho más inmediatas de esa inteligencia. Así si el hombre no fuese bípedo, no tendría manos con las que poder manipular y hacer cosas; un animal sin manos liberadas requeriría en su corporeidad de algún elemento que le facilitase el contacto físico con el entorno, función, entre otras, que desempeña el hocico ${ }^{23}$.

Otra vez Mengore. Víctima, acusador y juez. Quid est Veritas?, pregunta este. La Verdad tiene un nombre: Dios; y un Rostro. Jesucristo es

20 Belén Altuna. “El individuo y sus máscaras”. Ideas y Valores 140 (2009): 35-36.

${ }^{21}$ Es interesante lo que afirma san Agustín: «aunque también nuestro cuerpo de tal modo ha sido formado, que nos indica que somos de mejor condición que las bestias y, por tanto, semejantes a Dios, puesto que los cuerpos de todos los animales, sea de los que en el agua o en la tierra viven o de los que en el aire vuelan, tienen el cuerpo inclinado hacia la tierra y no erguido como está el cuerpo del hombre; por lo que se da también a entender que nuestra alma debe dirigirse hacia lo alto, es decir, debe estar levantada hacia las cosas espirituales eternas. Así precisamente se entiende, atestiguándolo también la forma erguida del cuerpo que, principalmente por el alma, el hombre fue hecho a imagen y semejanza de Dios» (De Genesi contra Manichaeos, I, 17,28).

22 Leonardo Polo. Quién es el hombre. Madrid: Ediciones Rialp, 1993, 67.

${ }^{23}$ No hay hocico en el hombre. El esculpido de su rostro viene caracterizado, entre otros rasgos, por unos pómulos salientes y la retracción del maxilar todo ello producto de la dinámica de la deposición/reabsorción de matriz ósea. Tiene lugar, por tanto, un desarrollo en la vertical —en lugar de la proyección horizontal propia del hocico- Se puede hablar de un proceso de «frontalización» (cf. José Ángel Lombo, y José Manuel Giménez. Biología y racionalidad. El carácter distintivo del cuerpo humano. Pamplona: EUNSA, 2016, 117). 
el Rostro de Dios. Cuando el hombre da la espalda a la verdad — como el acusador y el juez- el rostro se transforma en máscara. La mitología romana refería a unos espíritus atormentadores con el término larva; de acuerdo con Corominas, el latín larva significa espectro o máscara fantasmal: una apariencia de rostro, vacía en su interior ${ }^{24}$.

Rostro y persona quedan entonces dislocados: desaparece el carácter epifánico - teofánico, en realidad- de aquel; en su lugar queda una máscara dominada por la pasión: «el pecado introduce en el semblante (lik), que es la revelación purísima de la imagen de Dios, rasgos que son ajenos, extraños a este principio espiritual, y de este modo eclipsa la luz divina $»^{25}$.

La entrada del pecado hace que el hombre aparte la mirada de Dios; el rostro se enmascara, se hace, como el carbón, opaco a la luz; la máscara da expresión a la ausencia de vida, al vacío. La vocación del rostro humano es la de llegar a ser semblante, rostro transfigurado, diamante - siguiendo la metáfora de Soloviev- que se deja traspasar por la Luz del Mundo, Cristo ${ }^{26}$ :

«Soloviev dice que no es una idea la que se ha encarnado, sino el Hijo, una Persona. Se encarna para extender sobre nosotros su Vida. Cristo puede decir que es la Luz del mundo porque ha entrado en el hombre. Ilumina al hombre desde dentro porque nosotros somos el Cuerpo de Cristo ${ }^{27}$.

\subsection{De la imagen a la SEMEJanza}

La singularidad de la persona humana frente al resto de la creación queda ya enfatizada en los primeros pasajes de la Sagrada

${ }^{24}$ Joan Corominas. Breve diccionario etimológico de la lengua castellana. Madrid: Gredos, 1973, 354.

25 Pável Florenski. El iconostasio. Salamanca: Ediciones Sígueme, 2016, 58.

26 «En realidad, el misterio del hombre sólo se esclarece en el misterio del Verbo encarnado. Porque Adán, el primer hombre, era figura del que había de venir, es decir, Cristo nuestro Señor. Cristo, el nuevo Adán, en la misma revelación del misterio del Padre y de su amor, manifiesta plenamente el hombre al propio hombre y le descubre la sublimidad de su vocación» (Gaudium et spes, 22).

27 Marko Ivan Rupnik. La belleza, lugar de comunión. Última modificación: 8 de marzo de 2016. Fecha de consulta: 9 de julio de 2018. https://www.youtube.com/watch? $\mathrm{v}=\mathrm{wK} 2 \mathrm{gazqC} 89 \mathrm{M}$ 
Escritura donde el término hebreo bara' está recogido hasta tres veces en el relato sacerdotal de la creación del hombre (Gn 1,26-27) ${ }^{28}$. Afirma Tertuliano ${ }^{29}$ :

«Había uno a cuya imagen hacía [Dios al hombre], es decir, lo hacía a imagen del Hijo, que, teniendo que ser el hombre más auténtico y más verdadero, quiso que fuera llamada hombre su imagen, que en aquel momento debía ser formado del barro».

La verdadera imagen de Dios es Jesucristo; el hombre, en cambio, ha sido creado $a$ imagen de la imagen afirma santo Tomás de Aquino: el hombre es a imagen de Dios como la imagen del rey que hay en una moneda acuñada con su efigie; sin embargo, en Jesucristo la imagen de Dios se encontraría como la del rey en su hijo ${ }^{30}$.

El faciamus de Gn 1,26 denota y conlleva una especial dignidad en el hombre respecto al resto de las criaturas: es imagen y semejanza de Dios. Es entonces cuando surge la pregunta: «imagen» y «semejanza», ¿son términos más o menos sinónimos, o se debe entender alguna diferencia entre ellos?

La versión de los LXX emplea en Gn 1,26 los términos griegos eikón y homoíosis; la expresión homoíōsis Theo está muy presente en el pensamiento griego a partir, sobre todo, de Platón quien hablaba ya de «[... ] volverse semejante al dios en la medida de lo posible» señalando que "dicha semejanza es volverse justo y pío con sabiduría ${ }^{31}$. Este asemejarse es en realidad una evasión, un escapar de aquí abajo hacia allá arriba, esto es, un separarse de lo sensible, una separación del alma con respecto a su cuerpo. El término técnico para definir esta purificación es catharsis.

La idea de deificación la recogerán algunos Padres, dotándola de un sustrato cristiano. Así Ireneo de Lyon habla de un admirable intercambio: «Quien es Hijo de Dios se ha hecho Hijo del hombre, para que el hombre

${ }^{28}$ Masculum et feminam creavit eos (Gn 1,27). Para representar el amor fuerte y la misericordia de Dios su imagen ha de ser doble: el hombre, en su masculinidad, representa el amor de Dios en cuanto vigor y fidelidad; la mujer, en su feminidad, es la vertiente de la ternura y la bondad (cf. André Louf. El espíritu ora en nosotros. Madrid: Narcea, 2000, 81).

${ }_{29}$ Adversus Praxean, XII.

30 Cf. Summa Theologiae I, q. 35, a. 2, ad 3.

31 Teeteto, 176 b. También cf. Leyes 716 c-d; Timeo, 90d. 
reciba la adopción y llegue a ser hijo de Dios ${ }^{32}$. Si Ireneo no empleaba explícitamente el término, Clemente de Alejandría ya referirá expresamente la divinización del hombre: «El Logos de Dios se hizo carne a fin de que tú entendieras de un hombre cómo puede llegar a ser Dios» ${ }^{33}$.

Orígenes profundiza más: «la naturaleza humana, por su comunión con la divinidad, se torna divina no solo en Jesús, sino también en todos los que, después de creer, abrazan la vida que Jesús enseñó» ${ }^{34}$. Con san Atanasio y los Capadocios la doctrina de la theosis alcanza más precisión: «Dios se hace hombre para que el hombre se haga Dios» ${ }^{35}$.

La theosis griega responde a la deificatio latina. Si bien los teólogos del Occidente latino se focalizaron más en la teología de la gracia, liberadora del pecado, san Agustín se muestra conocedor de las aportaciones orientales sobre la doctrina de la deificación: «Si somos hijos de Dios, somos Dios» ${ }^{36}$.

Santo Tomás de Aquino considera la semejanza expresión y perfección de la imagen, perteneciente al amor de la virtud ${ }^{37}$. La imagen, fundamento objetivo, se manifiesta en la semejanza subjetiva, capacidad que queda neutralizada por el pecado. El proceso de asemejación a Dios solo es posible por medio de la gracia; es la vocación a desarrollar a lo largo de la vida ${ }^{38}$.

Cristo es la imagen del Dios invisible (Col 1,15); es el nuevo Adán y por tanto la respuesta última sobre el hombre (1 Cor 15,45-48):

«Él [Cristo] es el hombre definitivo, y la Creación es en cierto modo un anteproyecto de Él. Así podemos decir: el hombre es el ser que puede llegar a ser hermano de Jesucristo. Es la criatura que puede llegar a ser una con Cristo y en Él con Dios mismo» ${ }^{39}$.

\footnotetext{
${ }^{32}$ Adversus haereses, III, 19, 1.

33 Protreptico, I, 8, 4.

${ }^{34}$ Contra Celso, 3, 28.

35 De Incarnatione, 54, 3 (PG 25, 192B).

36 Enarrationes in Psalmos, 49, 2.

37 Ibid., I, q. 93, a. 9.

38 Catecismo de la Iglesia Católica, n. 1877.

39 Joseph Ratzinger. Creación y pecado. Pamplona: EUNSA, 2005, 74. En la misma línea, dice von Balthasar: «El "primer” Adán fue creado y configurado en vistas al segundo, a imagen y semejanza de un modelo de perfección que vendrá solo en el futuro y, por consiguiente, no es comprensible del todo por sí mismo, sino que solo puede ser comprendido al final en la figura del Hijo de Dios muerto y resucitado» (Hans Urs von Balthasar. El todo en el fragmento. Madrid: Ediciones Encuentro, 2008, 100).
} 
También en este sentido, afirma von Balthasar:

«[Dios] convierte al hombre mismo, con toda su incertidumbre, debilidad e imperfección, en el lenguaje con el que Él expresa la palabra de la salvación plena. Dios se sirve asimismo de una existencia distendida en el tiempo como de un escrito en el que imprime el signo de una eternidad supratemporal para el hombre y para el mundo [...]: el Hombre Jesús» ${ }^{40}$.

Aunque Evdokimov lo refiere al icono, bien puede decirse que también el rostro humano «extrae todo su valor teofánico de su participación en el "totalmente otro" por medio de la semejanza» ${ }^{41}$. El rostro humano está llamado a ser semblante y no máscara, dejándose transfigurar por medio de la gracia y de la virtud. En este sentido, afirma Florenski:

«[Imagen de Dios es] el don ontológico de Dios, el fundamento espiritual de cada persona como tal; mientras que por la segunda [semejanza de Dios] debe entenderse la potencia, la capacidad de perfeccionamiento espiritual, [...] la posibilidad de encarnar en la vida, en la persona, la imagen de Dios, que es nuestro bien secreto, y de este modo manifestarla en el rostro $»^{42}$.

La semejanza con Dios se realiza en una adhesión libre como imagen de la Trinidad: la persona humana se hace semejante a Dios cuando se entrega en el amor, en la comunión ${ }^{43}$.

\section{ROSTRO Y COMUNIÓN}

\subsection{Statio iv. Iesus fit Perdolenti Matri obviu}

«Ego autem sum vermis et non homo, opprobrium hominum et abiectio plebis. Omnes videntes me deriserunt me; torquentes labia moverunt caput: "Sperabit in Domino: eripiat eum, salvum faciat eum, quoniam vult eum” »(Sal 22,7-9). Si un ángel consoló a Cristo en Getsemaní (Lc 22,43), es María quien ahora acude.

\footnotetext{
40 Balthasar, 79.

41 Paul Evdokimov. El arte del icono. Madrid: Publicaciones Claretianas, 1991, 183.

42 Florenski. El iconostasio, 53.

${ }^{43}$ Cf. Marko I. Rupnik. El discernimiento. Burgos: Monte Carmelo, 2015, 19.
} 
Madre e Hijo se encuentran (fig. 2): los dos son portadores de la Cruz; no cruzan sus miradas, sino que las funden en la dirección de avance hacia el misterio pascual: llegar a la mañana de Resurrección implica pasar por el Gólgota.
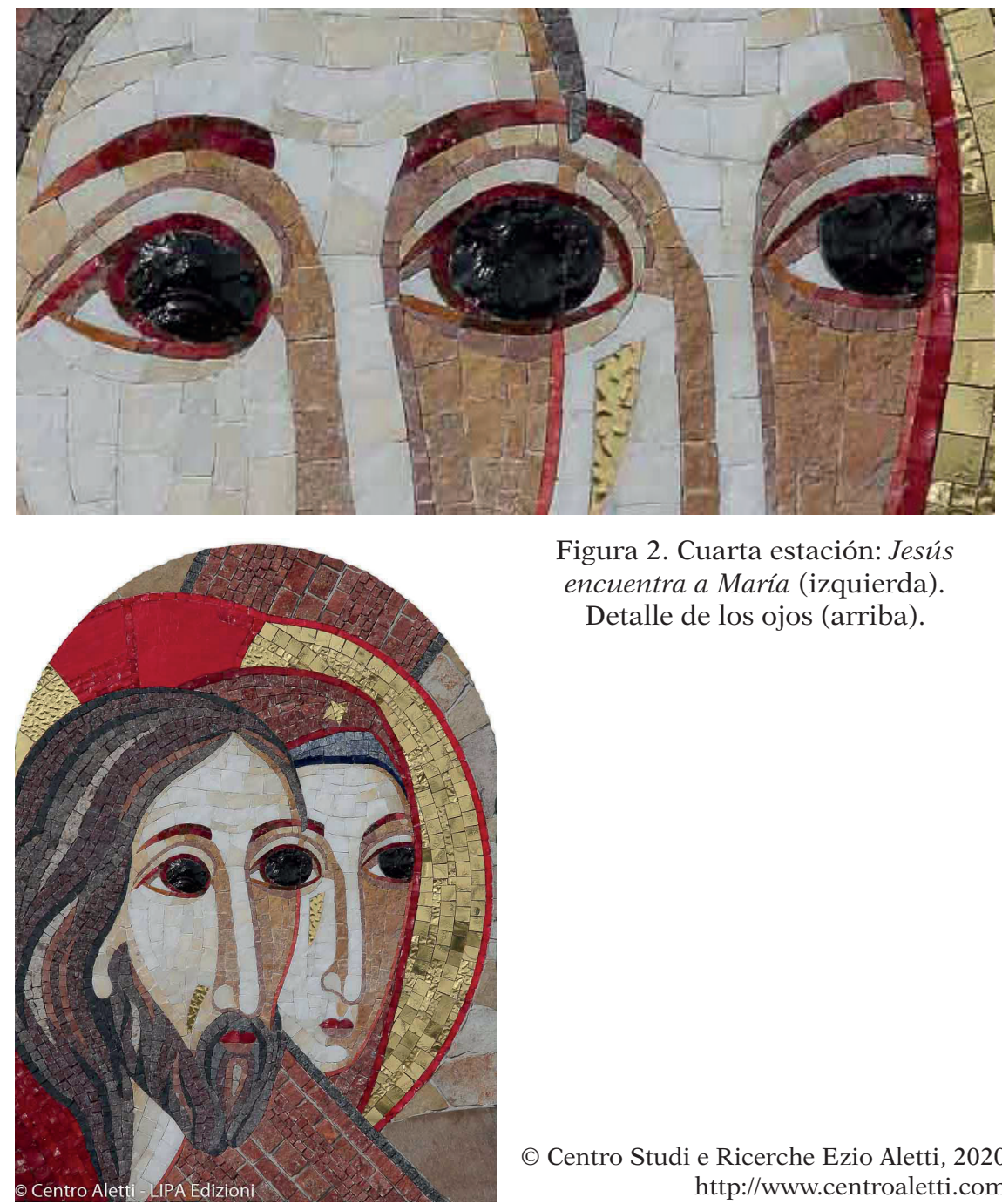

Figura 2. Cuarta estación: Jesús encuentra a María (izquierda). Detalle de los ojos (arriba).

(c) Centro Studi e Ricerche Ezio Aletti, 2020 http://www.centroaletti.com 
María lleva cubierta la cabeza con el maphorion, manto púrpura de dignidad de la realeza, y en cuya frente se distingue una estrella. Aunque en este tipo de iconografía al principio lo representado eran tres cruces - una en la frente y las otras en los hombros, en clara alusión a la Santísima Trinidad-, será en el periodo bizantino medio cuando se empiecen a reemplazar por estrellas. Si en la imagen de Mengore solo puede verse una es debido al encuadre compositivo.

Las estrellas también se han asociado como símbolos de la virginidad de María antes, durante y después del nacimiento de Cristo; virginidad luminosa, estrella que anuncia la llegada del sol. Comenta Galavaris que este símbolo no es de segundo orden porque lo es de la Gracia de la Trinidad luminosa, de la relación de María con la Trinidad ${ }^{44}$.

A continuación se revisan algunos de los tipos de representación de María con Jesús, con el objetivo de argumentar la novedad iconográfica —no ajena a la tradición- que presenta la estación iv de Mengore, y que se expone en el epígrafe subsiguiente.

\subsection{MAdRe e HiJo}

La iconografía mariana a lo largo de su recorrido histórico ha ido reuniendo una serie de prototipos o modos de representar a la Madre de Dios con su Hijo; entre otros, se quiere ahora destacar tres de ellos, propios del arte bizantino: Hodegetria, Eleousa y Strastnaia.

Virgen Hodegetria — «la que guía el camino»- debe su nombre a un icono que hubo en la iglesia constantinopolitana de Hodegon ${ }^{45}$, término en referencia a los monjes que guiaron a unos peregrinos ciegos hacia una fuente cuyas aguas podían sanarles la vista, y que se encontraba próxima al monasterio.

El prototipo Hodegetria presenta a María y Cristo-Niño de manera frontal a quien los mira. En este tipo de representación, las manos de ambos, altamente expresivas, cumplen dos funciones: comunicar y portar; en el primer caso, la mano de María se dirige hacia su Hijo, y Él da

${ }^{44}$ Cf. George Galavaris. Colours, Symbols, Worship: The Mission of the Byzantine Artist. London: The Pindar Press, 2012, 139.

${ }_{45}$ Cierta tradición atribuye su autoría a san Lucas (cf. Hans Belting. Imagen y culto: Una historia de la imagen anterior a la era del arte. Tres Cantos (Madrid): Akal, 2009, 102). 
la bendición; en el segundo, María lleva a Jesús, y Jesús porta un rollo y a veces un libro ${ }^{46}$. El paralelismo es elocuente: la Madre lleva al Hijo, y el Hijo trae la bendición del Padre; María porta al Verbo hecho carne; el Hijo es la Palabra.

Virgen Eleousa — de la ternura-. Sería una evolución de la anterior, donde ya afloran los sentimientos materno-filiales, como puede contemplarse en el famoso icono de la Virgen de Vladimir; ya no solo es skeno$m a$, sino también proairesis ${ }^{47}$ : el Niño acaricia a su Madre poniendo en contacto sus rostros. La imagen es enternecedora, pero el rostro de María -inclinado para recibir un beso del Niño- está absorto, con un aire de tristeza que incoa ya algo que se hará más patente en el tercer prototipo.

Virgen Strastnaia — de la Pasión-; es conocida también como Virgen del Perpetuo Socorro; el término strastnaia — ruso, a diferencia de los dos anteriores- significa «dolor». El Niño está asustado, ya no mira a su Madre, sino a los ángeles que le presentan los que serán los instrumentos de su Pasión: la caña y la esponja de vinagre, la lanza, la cruz y los clavos. La tensión de Jesús es manifiesta como revela el anclaje del pie derecho en el izquierdo y el modo en que se aferra con las dos manos a la de María — concretamente al pulgar-.

\subsection{La comunión de Mengore}

La esencia de la creatividad artística es la combinación: el sentido novedoso se extrae a partir de la integración y síntesis de elementos preexistentes. Lo ya conocido se combina para la obtención de lo nuevo.

Hay en la obra del padre Rupnik una sabiduría - artística y teológica a la par-capaz de integrar un sabor paleocristiano, románico, gótico y bizantino con un lenguaje visual familiar a las vanguardias de Van Gogh, De Stäel, Matisse o Jawlensky ${ }^{48}$. Si bien no se trata de la Madre y del Niño, el mosaico de la estación Iv reúne los prototipos marianos tra-

${ }^{46}$ Bissera V. Pentcheva. Icons and Power: The Mother of God in Byzantium. University Park, PA: The Pennnsylvania State University Press, 2006, 114.

${ }_{47}$ Kalavrezou, Ioli. "Images of the Mother: When the Virgin Mary Became Meter Theou". Dumbarton Oaks Papers 44 (1990): 169.

48 Cf. Mariano Apa. "Redemptoris Mater. Ecclesiae Gesamtkunstwerk". En La Capilla "Redemptoris Mater" del Papa Juan Pablo II, editado por Mariano Apa, Olivier Clément, y Crispino Valenziano, 247-248. Burgos: Monte Carmelo, 2002. 
dicionales bajo una nueva perspectiva: la de la comunión, inmanencia recíproca interpersonal:

«Los seres humanos, creados a imagen de Dios, son personas llamadas a gozar de la comunión y a desempeñar un servicio en un universo físico. Las actividades que derivan de la comunión interpersonal y del servicio responsable se refieren a las capacidades espirituales -intelectuales y afectivas- de las personas humanas, pero no excluyen el cuerpo» ${ }^{49}$.

La fuente de toda comunión es la mutua inhesión de las Personas divinas -lo que los griegos llamaron perichóresis y en el mundo latino se tradujo por circumincessio-:

«En Dios mismo se encuentra la imagen prototípica de lo que solo a modo de copia se lleva a cabo en la relación del hombre con Dios: en Dios tiene lugar el amor entre Padre e Hijo, Dios subsiste como don de la generación, y como acogida y retorno del engendrado en correspondencia perfecta, en la identidad del Espíritu de amor, que procede como único de la doble fuente del amor y como fruto eterno une y distingue los dos modos de subsistencia precedentes $»^{50}$.

Una de las soluciones iconográficas utilizadas para representar el ser trihipostático de Dios fue el modelo trifacial o vultus trifrons ${ }^{51}$, en el que una misma cabeza contenía los rostros idénticos de cada una de las tres personas, compartiendo cada una de ellas un ojo con la adyacente.

${ }^{49}$ Comunión y servicio: la persona humana creada a imagen de Dios. Comisión Teológica Internacional. Última modificación: 23 de julio de 2004. Fecha de consulta: 20 de julio de 2018. http://www.vatican.va/roman_curia/congregations/cfaith/cti_documents/rc_con_cfaith_doc_20040723_communion-stewardship_sp.html. En este sentido resulta de interés el pensamiento balthasariano que comenta Ruiz-Retegui: «El hombre nace a la conciencia de sí primariamente no como un "yo" sino como un "tú" de otra persona, como un ser interpelado» (Antonio Ruiz-Retegui. "Algunas consideraciones sobre la antropología implícita en la cristología de Hans Urs von Balthasar". Scripta Theologica 27 (1995): 468).

50 Balthasar, 85.

51 Este tipo de imágenes fue prohibida por Urbano VIII y Benedicto XIV, y es que la igualdad de las tres Personas no es identidad. Por otra parte este tipo de representación tiene antecedentes paganos e incluso diabólicos (cf. Raquel Rivera. “Tipos apofáticos de la Trinidad". En La visualidad del Logos, editado por Rafael García Mahíques, 186-193. Madrid: Ediciones Encuentro, 2015). 
Salvando las grandes distancias que se dan, el modelo «bifacial» de la cuarta estación podría intuirse como forma plástica de representar la comunión entre Madre e Hijo: junto con el hecho de estar sus cabezas dentro de un mismo nimbo crucífero, es significativa la fusión de uno de sus ojos al mirar en la misma dirección. No hay aquí un rechazo de la Verdad como en el caso de la estación I, por eso el ajuste de ambos globos oculares resulta perfecto (fig. 2).

María muestra el camino - Hodegetria-; la estrella de su maphorion lo ilumina en medio de la oscuridad. Ella es corredentora; la cruz no separa sus rostros sino que los une -Eleousa-. La tristeza latente en la iconografía tradicional, se convierte ahora en determinación por socorrer a su Hijo - Strastnaia, Perpetuo Socorro-; no solo en estar junto a Él, sino en Él.

\section{ALIQUA NOVATA FORMA DICENDI}

Aquellos instrumentos que asustaban a Jesús Niño y le hacían aferrarse al pulgar de su Madre, aparecen ahora en escena. Jesús es clavado en la cruz; el Rey va ser entronizado (Jn 19,19-22):

«La ironía joánica aparece una vez más en estas escenas. Cuando los judíos creen haber descartado a Jesús para que lo crucifiquen y los soldados se reparten sus vestidos, es entonces precisamente cuando Jesús es elevado y glorificado. La victoria de Jesús se da en la paradoja y cuando ya no se esperaba» ${ }^{52}$.

La obra de Rupnik se inspira en el arte del pasado pero sabiendo que se dirige al hombre del siglo XXI. La iconografía actual —reflejo de la posmodernidad- no gusta de los grandes relatos; más allá de lo meramente ilustrativo o didáctico, intenta concentrar lo narrativo en una imagen e, incluso, en un signo ${ }^{53}$.

Si bien puede decirse que la esencia plástica del vía crucis de Mengore es el rostro - los rostros silenciosos de Jesucristo y nueve personajes

52 Josep-Oriol Tuñí y Xavier Alegre. Escritos joánicos y cartas católicas. Estella: Verbo Divino, 1995, 74.

${ }^{53}$ Esto no es exclusivo del momento actual puesto que las primeras manifestaciones del arte paleocristiano se conocen como imágenes-signo precisamente por su simplicidad formal portadora de la fe de un pueblo. 
más-, este no aparece en los mosaicos de las estaciones xI (fig. 3a) y XII (fig. 3b). Se centran en una parte significativa del todo: son pura sinécdoque.

En realidad, todo el conjunto de Mengore resultaría sinecdóquico al prescindir de la representación del cuerpo entero centrándose en los rostros. En este sentido, también la estilización contribuye a que la sinécdoque se emplee como recurso de representación.
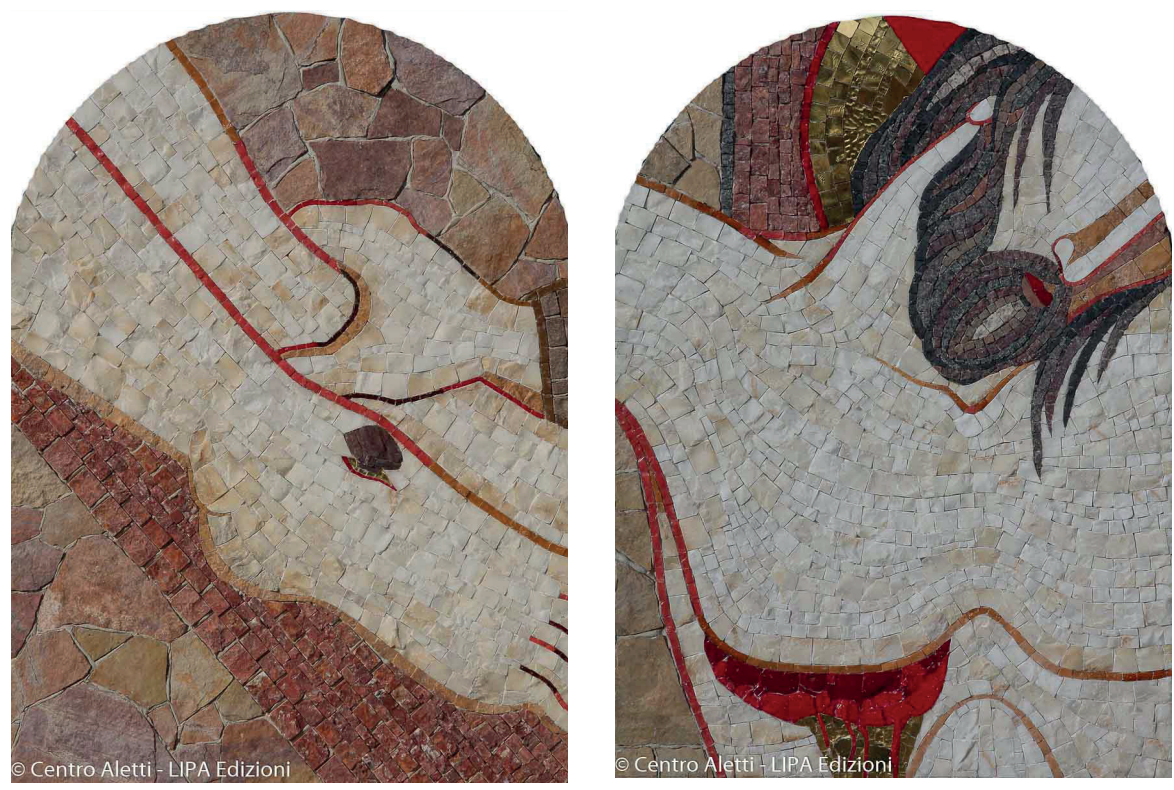

Figura 3. Decimoprimera estación: Jesús es clavado en la Cruz (izquierda), y decimosegunda: Muerte de Jesús en la Cruz (derecha)

(C) Centro Studi e Ricerche Ezio Aletti, 2020 http://www.centroaletti.com 
Las relaciones que establece el discurso connotativo del signo se alimentan de las figuras retóricas, las cuales pueden clasificarse en cuatro tipos: adjunción, supresión, sustitución e intercambio ${ }^{54}$.

Dentro de las figuras de sustitución o tropos está la sinécdoque. El término griego synekdókhe ${ }^{-55}$ designa un misterioso posicionamiento entre unidad y multiplicidad: una especial relación que posibilita el intercambio entre el todo y la parte; de acuerdo con Spang, una nueva forma de conocer, basada en una parte significativa en lugar de un todo asfixiante: «La sinécdoque no se basa exclusivamente en un expediente sustitutivo, además guarda siempre una relación de participación con lo aludido, solo es parcialmente sustitutiva ${ }^{56}$.

La sinécdoque sigue el principio lógico de inclusión: el todo es sustituido por la parte; hay un traslado cuantitativo entre el concepto pretendido y lo expresado de hecho: el mosaico de Mengore de la estación XI en la que Iesus clavis affigitur cruci muestra tan solo dos pies en diagonal: uno recién atravesado por un clavo; el otro a la espera de ser llagado. Todo queda dicho.

Lo mismo ocurre en la estación XII, Iesus moritur in cruce. La muerte de Jesús está connotada en una cabeza semioculta y, más aún, en la llaga de la lanza, que recibe el Hijo pero que vive solo la Madre: el costado abierto — oro y rojo — del nuevo Adán ${ }^{57}$, del que brota la Iglesia, nueva Eva:

«Cuanto más se parece la Iglesia a la Virgen, más se hace Esposa; cuanto más se hace Esposa, más se asemeja al Esposo, y cuanto más

54 Tal clasificación responde a la naturaleza de su operación. «Hay dos operaciones fundamentales: la adjunción [en la que] se añaden uno o varios elementos a la proposición; la supresión, [en la que] se quitan uno o varios elementos a la proposición. Y dos operaciones derivadas: la sustitución, que se analiza en una supresión seguida de una adjunción: se quita un elemento para reemplazarlo por otro; [y] el intercambio, que comprende dos sustituciones recíprocas: se permutan dos elementos de la proposición» (Jacques Durand. "Retórica e imagen publicitaria”. En Análisis de las imágenes, 81-112. Buenos Aires: Editorial Tiempo Contemporáneo, 1972; consultado en http://fba.unlp.edu.ar/lenguajemm/?wpfb_dl=50).

55 Corominas, 537.

56 Kurt Spang. "El todo y la parte. Alabanza a la sinécdoque". Cuadernos Empresa y Humanismo 123 (2014): 322.

57 «Era la Pascua, las campanas sonaban anunciando al Resucitado, cuando vi con claridad mis pecados sobre su Rostro. Y mientras sentía en el corazón "Vete en paz y no peques más", me pareció haber entendido para siempre al profeta que dice "Por sus llagas hemos sido curados"»(Rupnik. Los colores de la luz, 91). 
se asemeja al Esposo, más se asemeja a Dios: porque estas instancias superpuestas entre la Iglesia y Dios no son más que transparencias en las que se refleja el único esplendor de Dios ${ }^{58}$.

El uso de la sinécdoque se puede considerar un guiño a la inteligencia del observador por parte del artista. Todo proceso sinecdóquico está estrechamente relacionado con la elipsis, ante la necesidad de omitir un aspecto cuantitativo del todo. Si se compara la de Rupnik con la estación xi del vía crucis de Tiépolo - por referir un vía crucis más o menos tradicional-, sin desdeñar para nada la obra del pintor veneciano, se puede constatar el poder visual de la sinécdoque: la esencia tanto semántica como estructural queda plasmada de tal modo que hace difícil el olvido de esta imagen.

\section{PIEDRA, ROSTRO, EMOCIÓN}

Siguiendo a Arriola Jiménez, en la obra del padre Rupnik se distinguen tres estadios: abstracto, figurativo y litúrgico ${ }^{59}$. Este último en general, y el vía crucis de Mengore en particular, está ejecutado en forma de mosaico. Lejos del mero capricho estilístico o de la marca de identidad del artista, hay una profunda riqueza encerrada en esta opción, empezando por su alegato de la importancia del amor por la realidad y del respeto al ritmo propio de las $\operatorname{cosas}^{60}$.

Es el lenguaje del mosaico, en los fragmentos de roca que los configuran, reflejo de un arte coral, expresión de comunión en las alteridades

${ }^{58}$ Charles Journet. L'Église du Verbe Incarné, II, 432-433. Citado en Ignacio de la Potterie. María en el misterio de la Alianza, 275. Madrid: BAC, 1993.

59 Cf. María Arriola Jiménez. "La obra inicial de Marko Ivan Rupnik y su vinculación con el arte contemporáneo". En Tradición y modernidad en la obra de Marko Ivan Rupnik. Implicaciones teológicas, estéticas e iconográficas de los mosaicos del Centro Aletti (Roma), coordinado por María Rodríguez Velasco, 25-74. Madrid: CEU Ediciones, 2013.

${ }^{60}$ Esta reivindicación tiene especial importancia en el contexto actual de la cultura de lo virtual y del dominio caprichoso del mundo a golpe de pantalla. Los perfiles o avatares tan extendidos en las redes sociales, en muchos casos, no son sino una máscara que oculta a la persona. En este sentido, la tecnología facilita la propensión a conductas no éticas por crear lo que podría referirse como una distancia moral entre un acto y la responsabilidad (moral) del mismo; es la seguridad de la máscara que esconde a la persona. 
—como la Iglesia-. Pero también es el que plasma mejor la aspiración de la materia a ser transfigurada (cf. Rom 8,20-21):

«El primer significado simbólico no radica en el color o en el trazo, sino en la dura, opaca e intransitable materia que los sustenta, y que en cuanto fundamento, precisamente, y no mero soporte técnico, también, de algún modo, los "produce" ${ }^{61}$.

Solo el hombre es imago Dei; pero el término vestigium refiere una cierta dignidad en el resto de la creación material ${ }^{62}$, no del todo ajena a lo personal, al haber salido de las manos del Padre por medio de su Verbo: «Hágase, pues — dijo el Padre—, / que tu amor lo merecía»; / y en este dicho que dijo, / el mundo criado había / palacio para la esposa / hecho en gran sabiduría» ${ }^{63}$.

El mosaico deja translucir todo esto. El hacer plástico del artista-teólogo esloveno muestra siempre en la parte que podría denominarse decorativa un gran dinamismo, mientras que en el caso del rostro, la materia cede ante la expresión de la persona, —se amasa en un «tú», en palabras de Rupnik - haciéndose invisible la textura de la roca:

«Toda la materia se mueve hacia el hombre, querría entrar en el cuerpo, hacerse cuerpo, porque el cuerpo es portador del Espíritu, participa por lo tanto en el amor de Dios y en la posibilidad de estar al servicio del amor, ser absorbido por él y participar por lo tanto en la resurrección y en la vida eterna» ${ }^{64}$.

Esta idea también la glosa Ayán de la Primera apología de Justino:

«El rostro humano con su respiración sería un símbolo de la función del Verbo en el cosmos: de una parte, se significaría la figura de la cruz y, de otra parte, la unción por la que el Verbo hace partícipes a las criaturas de su propia unción, la que recibió de manera única antes de la creación del mundo» ${ }^{65}$.

${ }^{61}$ Massimo Cacciari. "William Congdon: analogía del icono". Revisiones 2 (2006): 113-118.

62 Summa Theologiae I, q. 93, a. 6.

63 Juan de la Cruz. "In principio erat verbum, acerca de la Santísima Trinidad". En Poesía, editado por Domingo Ynduráin, 285. Madrid: Cátedra, 1984.

64 Špidlík y Rupnik. Teología de la evangelización, 310.

65 Juan José Ayán. iQué bueno es sentir sed de Dios! La Aguilera (Burgos): Instituto Iesu Communio, 2016, 90. 
Los rostros de Mengore son prácticamente bidimensionales, lo que facilita el encuentro, la presencia: no se mira a través de una ventana, sino que se está ante alguien que interpela al observador, unos ojos que miran al peregrino; antes de que este los vea, es visto ${ }^{66}$. Precisamente, la importancia de los ojos dentro del rostro yace en que es en ellos donde se capta la presencia. En este sentido, cuenta el padre Rupnik lo que le dijo en una ocasión un arquitecto:

"Yo no soporto tu arte con esos rostros límpidos y esos colores solares, porque creo que todo es una fantasía. Prefiero hacer espacios desiertos y austeros, porque creo que después de la muerte no hay nada y yo estaré allí, recostado en el vacío ${ }^{67}$.

Podría decirse que los mosaicos de Rupnik no causan emoción: su plasticidad no arrastra; no es invasiva, ni impositiva, sino que se muestra respetuosa con la libertad de quien lo observa. No obstante, tampoco se está ante una obra muda porque expresa emoción: una serenidad triste que se dibuja en los rostros. Esto, más allá del conjunto de Mengore, se extiende al resto de sus obras a lo largo de todo el mundo. ¿Por qué?

Para quien está alegre en su espíritu y se dirige al encuentro de Cristo, el velo de tristeza de la imagen no le resultará molesto; en cambio, si se trata de una alegría más sensual, el rostro apelará a la sobriedad. Pero, si quien acude al encuentro de este rostro es una persona herida, triste, la mirada percibida será de compasión y paz: «te ha tomado en la angustia y te lleva a la luz de la aurora; te ha tomado en la noche y te lleva a la mañana... ¡Este es el tránsito! Este es el arte del rostro de Cristo ${ }^{68}$.

${ }^{66}$ Perspectiva precisamente significa «mirar a través» y en tal sentido puede considerarse como un orden de apariencias visuales, no del verdadero ser de las cosas. Por el contrario, es constante en la tradición del icono el empleo de lo que se ha dado en llamar la perspectiva invertida o conversa, en la que lo representado converge hacia quien contempla. De acuerdo con Florenski, uno de los modos habituales en los que se ejecuta esta clase de perspectiva es el de presentar centros múltiples, como podrían ser los llamativos ojos de aquellos mosaicos de Mengore en los que aparecen dos o más rostros. Sobre la perspectiva invertida cf. Pavel Florenski. La perspectiva invertida. Madrid: Ediciones Siruela, 2005, 25-28.

${ }_{67}$ Nataša Govekar. El rojo de la Plaza de Oro. Entrevista de Natasa Govekar con Marko Ivan Rupnik sobre arte, fe y evangelización. Burgos: Monte Carmelo, 2013, 62.

${ }^{68}$ Ibid., 165. 


\section{CONCLUSIÓN}

Siguiendo el pensamiento balthasariano, la humanidad es el lenguaje que Dios ha querido para expresar el diálogo eterno - la comunión- del Padre y del Hijo en el ámbito extradivino; podría hablarse — siempre de manera limitada y torpe- de una «transcripción», en la diástasis temporal, de la vida del Hijo de Dios en la eternidad.

El hombre es lenguaje y como tal hay en él una «dimensión retórica». El diablo lo sabía y tentó a nuestros primeros padres con una figura retórica, concretamente una comparación (paralelismo): «et eritis sicut Deus»(Gn 3,5). En este caso se produce una operación de adjunción; hay una yuxtaposición, pero no una comunión. No ocurre lo mismo con la sinécdoque, donde el todo está incluido en la parte. Esta es la lección que de un modo visual se puede extraer del proyecto iconográfico del vía crucis de Mengore.

Tradición y contemporaneidad quedan armonizadas en la obra artística del padre Rupnik ${ }^{69}$. Pero no se trata de un arte fácil ${ }^{70}$; la riqueza teológica que encierra está oculta bajo el «velo» de un dibujo esencializado que ante una mirada superflua podría parecer ingenuo. No presenta un elevado grado de realismo, pero tampoco se está ante una abstracción total, como podría ser el caso del vía crucis de Barnett Newman.

Esta posición intermedia, en lo que al grado de iconicidad se refiere, es la opción plástica que Rupnik adopta para expresar la riqueza del mundo personal, la cual no se comunica tanto en la forma - que actúa de manera más aislada-, sino en la relación, más dinámica y simbólica.

La fe cristiana está vinculada a la encarnación y a la transfiguración; en este sentido, podría ser cuestionable pensar que cuanto más abstracta es una obra, más espiritual resulta ${ }^{71}$. Si ello fuese así, Dios no se habría

${ }^{69}$ Cf. María Rodríguez Velasco (coord.). Tradición y modernidad en la obra de Marko Ivan Rupnik.

${ }^{70}$ Cf. María Ruiz de Loizaga. "Hacia un arte litúrgico, según la concepción de Marko Ivan Rupnik. Reflexiones sobre el arte sacro". Scripta Theologica 49, n. 3 (2017) 629-630.

${ }^{71}$ En opinión de Camón Aznar, la raíz de la abstracción hay que buscarla en el idealismo alemán y su concepto de libertad como último fin del hombre, absoluta posesión de sí mismo; ser se reduce a obrar, y el balbuceo se convierte en la forma de expresión por antonomasia (cf. José Camón Aznar. Filosofía del arte. Madrid: Espasa-Calpe, 1974, 67-69). 
encarnado ${ }^{72}$. Esto no ocurre en las obras del artista y teólogo esloveno; la elegante estilización de su gramática composicional unida a lo que podría catalogarse como «luminosidad ontológica» son mistagogía, camino hacia el Misterio ${ }^{73}$.

Como ya se ha referido más arriba, la retórica visual de Mengore - en las estaciones XI y XII, y, en general, de todo el conjunto basado en los rostros- hace uso de la sinécdoque por tratarse de una figura o tropo basado en la lógica de la inclusión; es la manera plástica de presentar la novedad del acontecimiento de Cristo que es precisamente tropo, el modo de existir que incluye al otro ${ }^{74}$. Rupnik refiere aquí unas palabras de Soloviev:

«La belleza para nosotros cristianos es cuando dentro de las cosas veo el rostro; cuando las cosas se vuelven sutiles, y yo veo a través de ellas y todo el mundo se vuelve un iconostasio, una luz que viene desde dentro; es una luz cálida, que te envuelve y que te enamora. La belleza de la comunión» ${ }^{75}$.

Comunión no se trata del ser-para-otro del que habla Lévinas, donde una relación asimétrica ${ }^{76}$ yo-otro, sin reciprocidad alguna, daría prioridad absoluta al otro dejando la responsabilidad al yo. Comunión es inmanencia recíproca interpersonal fruto del amor — don y acogida-.

Es en la mirada donde se sintetiza el posicionamiento personal en la existencia: vivir en Cristo (comunión) o rechazar la luz de su mirada (solus ipse sum):

«El Salvador [...] está presente en todos cuanto viven en Él, de tal manera que atiende a todas sus necesidades y es todo para ellos. No les deja volver a otra cosa su vista, ni buscar nada en parte alguna fuera

72 Govekar, 55.

73 «La iconografía de hoy deja de ser didáctica y narrativa para hacerse mistagógica y contemplativa» (Juan Plazaola. "El rostro de Cristo en el arte contemporáneo". Ars sacra 6 (1998): 30-40).

74 "El hombre es un ser "teotropo"» (Henri de Lubac. El drama del humanismo ateo. Madrid: Ediciones Encuentro, 2012, 314).

${ }^{75}$ Rupnik. "La belleza, lugar de comunión" (Conferencia en la Pontificia Universidad Católica de Chile - Campus Lo Contador - 8 de marzo de 2016), https://www. youtube.com/watch?v=wK2gazqC89M

${ }^{76}$ Cf. Emmanuel Lévinas. Totalidad e infinito. Salamanca: Ediciones Sígueme, 2002, 228-229. 
de Él. [...] Es el ojo que en ellos contempla la luz con que miran y el objeto en la visión contemplado ${ }^{77}$.

En la existencia a contraluz la persona queda como mero individuo: su rostro queda oculto, "porque la luz es la capacidad de la realidad de ser manifestada; la tiniebla, por el contrario, es el aislamiento, la escisión de la realidad, la imposibilidad de la manifestación recíproca, y por tanto la invisibilidad de uno respecto a otro ${ }^{78}$. La vocación de semblante queda frustrada; el rostro se convierte en máscara:

«Si aparece que la imagen de Dios latente no se ha manifestado concretamente, como semejanza divina, si el hombre ha escondido en tierra el don de la imagen de Dios, [...] si no ha llevado a cabo la prueba de sí mismo, entonces la imagen de Dios será sustraída de su aseidad no divinizada; pero si la aseidad ha sido transformada en semejanza de Dios, entonces el hombre recibirá [...] la bienaventuranza interior que consiste en ver realizada en uno mismo la semejanza divina, la alegría creadora del artista que contempla su obra ${ }^{79}$.

\section{REFERENCIAS}

Altuna, Belén. "El individuo y sus máscaras". Ideas y Valores 140 (2009): 33-52.

Apa, Mariano. "Redemptoris Mater. Ecclesiae Gesamtkunstwerk". En La Capilla "Redemptoris Mater" del Papa Juan Pablo II, editado por Mariano Apa, Olivier Clément, y Crispino Valenziano, 241-267. Burgos: Monte Carmelo, 2002.

Arriola Jiménez, María. "La obra inicial de Marko Ivan Rupnik y su vinculación con el arte contemporáneo". En Tradición y modernidad en la obra de Marko Ivan Rupnik. Implicaciones teológicas, estéticas e iconográficas de los mosaicos del Centro Aletti (Roma), coordinado por María Rodríguez Velasco, 17-78. Madrid: CEU Ediciones, 2013.

Ayán, Juan José. ;Qué bueno es sentir sed de Dios! La Aguilera (Burgos): Instituto Iesu Communio, 2009.

77 Nicolás Cabasilas. La vida en Cristo. Madrid: Ediciones Rialp, 1999, 26.

78 Pável Florenski. La columna y el fundamento de la Verdad. Salamanca: Ediciones Sígueme, 2010, 179.

79 Ibid., 220. 
Balthasar, Hans Urs von. El todo en el fragmento. Madrid: Ediciones Encuentro, 2008.

Belting, Hans. Imagen y culto: Una historia de la imagen anterior a la era del arte. Tres Cantos (Madrid): Akal, 2009.

Burgos, Juan Manuel, ed. La filosofía personalista de Karol Wojtyla. Madrid: Palabra, 2011.

Cabasilas, Nicolás. La vida en Cristo. Madrid: Ediciones Rialp, 1999.

Cacciari, Massimo. "William Congdon: analogía del icono". Revisiones 2 (2006): 113-118.

Camón Aznar, José. Filosofía del arte. Madrid: Espasa-Calpe, 1974.

Comisión Teológica Internacional. "Comunión y servicio: la persona humana creada a imagen de Dios". Última modificación: 23-VII-2004. Fecha de consulta: 20-VII-2018 http://www. vatican.va/roman_curia/congregations/cfaith/cti_documents/ rc_con_cfaith_doc_20040723_communion-stewardship_sp.html.

Corominas, Joan. Breve diccionario etimológico de la lengua castellana. Madrid: Gredos, 1973.

Durand, Jacques. "Retórica e imagen publicitaria". En Análisis de las imágenes, 81-112. Buenos Aires: Editorial Tiempo Contemporáneo, 1972.

Evdokimov, Paul. El arte del icono. Madrid: Publicaciones Claretianas, 1991. Florenski, Pável. La perspectiva invertida. Madrid: Ediciones Siruela, 2005. Florenski, Pável. La columna y el fundamento de la Verdad. Salamanca: Ediciones Sígueme, 2010.

Florenski, Pável. El iconostasio. Salamanca: Ediciones Sígueme, 2016.

Galvaris, George. Colours, Symbols, Worship: The Mission of the Byzantine Artist. London: The Pindar Press, 2012.

Govekar, Nataša. El rojo de la Plaza de Oro. Entrevista de Nataša Govekar con Marko I. Rupnik, sobre arte, fe y evangelización. Burgos: Monte Carmelo, 2013.

Journet, Charles. L'Église du Verbe Incarné, II. Citado en María en el misterio de la Alianza, de Ignacio de la Potterie, 275. Madrid: BAC, 1993.

Juan de la Cruz. "In principio erat verbum, acerca de la Santísima Trinidad". En Poesía, editado por Domingo Ynduráin. Madrid: Cátedra, 1984.

Kalavrezou, Ioli. "Images of the Mother: When the Virgin Mary Became Meter Theou". Dumbarton Oaks Papers 44 (1990): 169.

Labarga, Fermín. "El rostro de Cristo en el arte". Anuario de Historia de la Iglesia 25 (2016): 265-316. DOI: https://doi.org/10.15581/007.25.265-316 
Lévinas, Emmanuel. Humanismo del otro hombre. México: siglo veintiuno editores, 1974.

Lévinas, Emmanuel. Totalidad e infinito. Salamanca: Ediciones Sígueme, 2002.

Lévinas, Emmanuel. Ética e infinito. Boadilla del Monte: A. Machado Libros, 2008.

Lombo, José Ángel, y José Manuel Giménez. Biología y racionalidad. El carácter distintivo del cuerpo humano. Pamplona: EUNSA, 2016.

Louf, André. El espíritu ora en nosotros. Madrid: Narcea, 2000.

Lubac, Henri de. El drama del humanismo ateo. Madrid: Ediciones Encuentro, 2012.

Marías, Julián. Antropología metafísica. Madrid: Ediciones de la Revista de Occidente, 1970.

Marini, Piero. The Way of the Cross. Office for the Liturgical Celebrations of the Supreme Pontiff. Última modificación: 1-II-2011. Fecha de consulta: 15-I-2018. http://www.vatican.va/news_services/liturgy/ documents/ns_lit_doc_via-crucis_en.html

Millán-Puelles, Antonio. La estructura de la subjetividad. Madrid: Ediciones Rialp, 1967.

Pentcheva, Bissera V. Icons and Power: The Mother of God in Byzantium. University Park, PA: The Pennnsylvania State University Press, 2006.

Plazaola, Juan. "El rostro de Cristo en el arte contemporáneo". Ars sacra 6 (1998): 30-40.

Polo, Leonardo. Quién es el hombre. Madrid: Ediciones Rialp, 1993.

Potterie, Ignacio de la. María en el misterio de la Alianza. Madrid: BAC, 1993.

Ratzinger, Joseph. Creación y pecado. Pamplona: EUNSA, 2005.

Rivera, Raquel. "Tipos apofáticos de la Trinidad”. En La visualidad del Logos, editado por Rafael García Mahíques, 150-207. Madrid: Ediciones Encuentro, 2015.

Rodríguez Velasco, María (coord.). Tradición y modernidad en la obra de Marko Ivan Rupnik. Implicaciones teológicas, estéticas e iconográficas de los mosaicos del Centro Aletti (Roma). Madrid: CEU Ediciones, 2013.

Ruiz de Loizaga, María. "Hacia un arte litúrgico, según la concepción de Marko Ivan Rupnik. Reflexiones sobre el arte sacro". Scripta Theologica 49, n. ${ }^{\circ} 3$ (2017): 619-643. DOI: https://doi.org/10.15581/006.49.3.619-643.

Ruiz de Loizaga, María. "La reinterpretación del descenso de Cristo a los infiernos en los mosaicos litúrgicos del Centro Aletti". Estudios 
Eclesiásticos, n. ${ }^{\circ} 94$ (2019): 443-475. DOI: https://doi.org/10.14422/ ee.v94.i370.y2019.001.

Rupnik, Marko Ivan. Los colores de la luz. Burgos: Monte Carmelo, 2003. Rupnik, Marko Ivan. El discernimiento. Burgos: Monte Carmelo, 2015. Rupnik, Marko Ivan. El camino de la vocación cristiana. Madrid: BAC, 2016. Rupnik, Marko Ivan. "La belleza, lugar de comunión”. Última modificación: 8 de marzo de 2016. Fecha de consulta: 9 de julio de 2018. https://www. youtube.com/watch?v=wK2gazqC89M.

Scruton, Roger. El alma del mundo. Madrid: Ediciones Rialp, 2016.

Spang, Kurt. "El todo y la parte. Alabanza a la sinécdoque". Cuadernos Empresa y Humanismo 123 (2014): 321-332.

Špidlík, Tomáš, y Marko Ivan Rupnik. Teología de la evangelización desde la belleza. Madrid: BAC, 2013.

Tuñí, Josep-Oriol, y Xavier Alegre. Escritos joánicos y cartas católicas. Estella: Verbo Divino, 1995.

Wojtyla, Karol. Amor y responsabilidad. Madrid: Editorial Razón y Fe, 1978.

Wojtyla, Karol. Persona y acción. Madrid: Palabra, 2011. 